\title{
Thermographic analysis in ultrasonic fatigue tests
}

\author{
H. XUE ${ }^{1,2}$, D. WAGNER ${ }^{3}$, N. RANC ${ }^{3}$ and E. BAYRAKTAR ${ }^{1,2}$ \\ ${ }^{1}$ Supmeca/LISMMA-Paris, School of Mechanical Engineering, St-Ouen, France, ${ }^{2}$ ITMA/CNAM-Arts et Métiers, Laboratory of Fatigue and fracture \\ mechanics, Paris, France, ${ }^{3}$ LEEE E.A.387, Université Paris X, Ville D'avray, France
}

Three kinds of alloys used in the automotive industry for structures and engine components are subjected to very high cycle fatigue damage during working service. In the study, fatigue damage progression of the three kinds of alloys was investigated in the very high cycles fatigue regime by means of thermographic analysis. The specimens have been tested at ambient temperature without cooling air using a piezoelectric fatigue system $(20 \mathrm{kHz})$ with a stress ratio of $R$ $=-1$ to determine the effects of increased specimen temperature caused by internal damping due to cycling at a very high frequency. The temperature evolution of specimens for different alloys at various load levels have been recorded. Results indicated that the temperature evolution of the fatigue specimen de-pends on the material, testing frequency and loading level; the temperature increased just at the beginning of the test, which corresponds to the thermal dissipation in the specimen. In the process of small crack propagation, the temperature in a local plastic zone increased sharply, evidently irreversible local plastic deformation can result in a local temperature increase. The basis of microstructural characterization and fracture surface analysis by scanning electron microscopy, it was found that the temperature field in an ultrasonic fatigue specimen corresponds to the fatigue damage process.

Keywords crack initiation; gigacycle fatigue regime; thermal dissipation.

\section{INTRODUCTION}

Early in the 1990s, it was proved by Bathias that metals fail at up to $10^{10}$ cycles and beyond, many materials, including some steels, and cast iron exhibit a sharp decrease on fatigue strength between fatigue lives of $10^{6}$ and $10^{10}$ cycles. This is in contrast to the classical fatigue limit, which assumes a constant minimum fatigue strength below which a material is assumed to have an infinite life. In order to explain the gigacycle fatigue regime, high-frequency fatigue testing is mandatory. However, high-frequency fatigue loading is always associated with thermal dissipation in metals and a rise in temperature. Even in case of confined plasticity or microplasticity the thermal dissipation is not negligible and anyway it is an excellent parameter to understand and follow the fatigue damage. For example, Paris' model for fish-eye formation in the gigacycle fatigue regime showed that initiation takes a very long time and propagates a small number of cycles. ${ }^{1}$

Temperature evolution of specimen is a real phenomenon under the cyclic loading in gigacycle regime

Correspondence: H. Xue. E-mail: bayraktar@supmeca.fr that is not well known. This phenomenon is not only affected by heat and mechanical deformation, but stress amplitude, loading frequency and the heat transmitted in the fatigue process will influence the temperature evolution of test materials. In fact, the energy dissipation results in an increase in of temperature of the specimen in the ultrasonic fatigue experiments. In other words, fatigue damage process is a complicated energy dissipation process. There are several kinds of energy present in the fatigue process; including elastic strain energy, plastic strain energy and anelasticity and heat dissipation. $^{2-8}$

High-performance materials (e.g. high-strength steel), which are particularly important for automobile design are subjected to very high cycle fatigue loading during their working service, under high cycle fatigue conditions, more than $90 \%$ of the fatigue life is spent before cracks can be detected. So, it is necessary to detect crack nucleation and small crack growth by measuring the temperature field in an ultrasonic fatigue specimen in order to characterize the changes in the material at the submicrostructure level, which lead to crack initiation. 
In the current study, the heat dissipation of steel (AISI 52100 and 42CD4) and cast iron (GS51) specimens are tested at $20 \mathrm{kHz}$ frequency; the temperature evolution is measured by an advanced infrared imaging system; the energy dissipation in the ultrasonic fatigue test were analysed. The influence factor for energy dissipation and the effect of energy dissipation on fatigue properties is discussed in detail, finally, the fatigue damage process will be characterized based on thermographs of the fatigue specimen.

\section{EXPERIMENTAL CONDITIONS}

\section{Materials and fatigue test}

The test materials were a high-strength steel AISI-52100, a 42CD4 steel that had been treated in a different heat treatment condition (heat treatment condition shown in Table 1) and a cast iron without heat treatment. Their chemical compositions, fatigue test conditions and mechanical properties of the materials studied here are given in Tables 2 and 3, respectively. The microstructures of the 42CD4 and the AISI-52100 were martensite (Fig. 1). The microstructure of cast iron with spheroid graphite is

Table 1 Heat treatment condition of materials

\begin{tabular}{ll}
\hline Materials & Heat treatment summary \\
\hline AISI 52100 & $\begin{array}{r}\text { Annealed at } 850^{\circ} \mathrm{C} / 16 \text { min, quench at } 200 \\
{ }^{\circ} \mathrm{C} / 4 \text { min, cooled in air and tempering } \\
\text { at } 170{ }^{\circ} \mathrm{C} / 1 \mathrm{~h}\end{array}$ \\
& $\begin{array}{r}\text { Annealed at } 850^{\circ} \mathrm{C} / 30 \mathrm{~min} \text {, quench in oil } \\
\text { and tempering at } 4300^{\circ} \mathrm{C} / 1 \mathrm{~h}\end{array}$ \\
42CD4 (a) & \\
\hline
\end{tabular}

composed of perlite (95\%) and ferrite (5\%). Mainly, ferrite islands surrounding spheroid graphite (white zone around graphite is shown in Fig. 2). The specimens from 42CD4 were prepared to be transversal $(\mathrm{T})$ with respect to the rolling direction. The specimens tested at an ultrasonic fatigue frequency of $20 \mathrm{kHz}$ with a stress ratio of $R=-1$ (tension-compression) under load control without cooling. The mechanisms of fatigue failure were studied by means of analysis of fractography on the scanning electron microscope. The fracture origin and/or inclusions were identified by the use of energy dispersion analysis.

The dimensions of the ultrasonic fatigue specimen had been calculated to satisfy the resonance vibration condition with $20 \mathrm{kHz}$, the geometry is shown in Fig. 3, for these three kinds of materials, the specimen has the same diameter ( $R 1$ and $R 2)$ and $R$, the resonance length of the specimen can be calculated according to the material properties.

\section{Temperature measurements}

In order to determine the temperature field on the specimen surface, a non-destructive measurement technique was chosen using an infrared pyrometer. During the fatigue test, the temperature varies between the ambient and approximately $200{ }^{\circ} \mathrm{C}$. The spectral range of the radiation emitted by the specimen is in the mid-infrared domain associated with a mercury cadmium telluride detector. Also, an infrared camera was used in this study, which is made up of a matrix of $320 \times 240$ detectors. This method allows the visualization of the temperature cartography with very good time and spatial resolutions. In our case, the spatial resolution is $0.17 \mathrm{~mm}$ and the aperture time can vary between $100 \mu$ s (lower than 1 cycle period) and $1500 \mu \mathrm{s}$

Table 2 Chemical composition of materials (wt\%)

\begin{tabular}{llllllllll}
\hline Steel grade & $\mathrm{C}$ & $\mathrm{Mn}$ & $\mathrm{P}$ & $\mathrm{S}$ & $\mathrm{Si}$ & $\mathrm{Mg}$ & $\mathrm{Ni}$ & $\mathrm{Cr}$ & $\mathrm{Cu}$ \\
\hline 42CD4 & 0.428 & 0.827 & 0.012 & 0.024 & 0.254 & & 0.173 & 1.026 & \\
AISI 52100 & 1.03 & 0.339 & 0.012 & 0.008 & 0.242 & & 0.147 & 1.461 & 0.224 \\
Cast iron GS51 & 3.65 & 0.5 & & & 2.49 & 0.04 & & & 0.7 \\
\hline
\end{tabular}

Table 3 Fatigue test conditions and mechanical properties of the materials

\begin{tabular}{|c|c|c|c|c|c|c|}
\hline Test number & Material & $\begin{array}{l}\text { Stress amplitude } \\
\text { in } \mathrm{MPa}\end{array}$ & $\begin{array}{l}\text { Cycle number at the } \\
\text { end of the test }\end{array}$ & $\mathrm{E}(\mathrm{GPa})$ & UTS (MPa) & Fracture \\
\hline 1 & AISI 52100 & 210 & $9.8 \times 10^{6}$ & 210 & 2358 & No \\
\hline 2 & AISI 52100 & 500 & $1.5 \times 10^{7}$ & & & No \\
\hline 3 & GS51 cast iron & 120 & $1.3 \times 10^{9}$ & 169 & 795 & No \\
\hline 4 & GS51 cast iron & 210 & $5.3 \times 10^{6}$ & & & Yes \\
\hline 5 & $42 \mathrm{CD} 4$ steel & 425 & $7.1 \times 10^{7}$ & 210 & 1508 & Yes \\
\hline 6 & $42 \mathrm{CD} 4$ steel & 460 & $3.1 \times 10^{5}$ & & & Yes \\
\hline
\end{tabular}


Fig. 1 Optical micrographs (a) AISI 52100 microstructure with small inclusion. (b) 42CD4 microstructure with $\mathrm{MnS}$ inclusion.

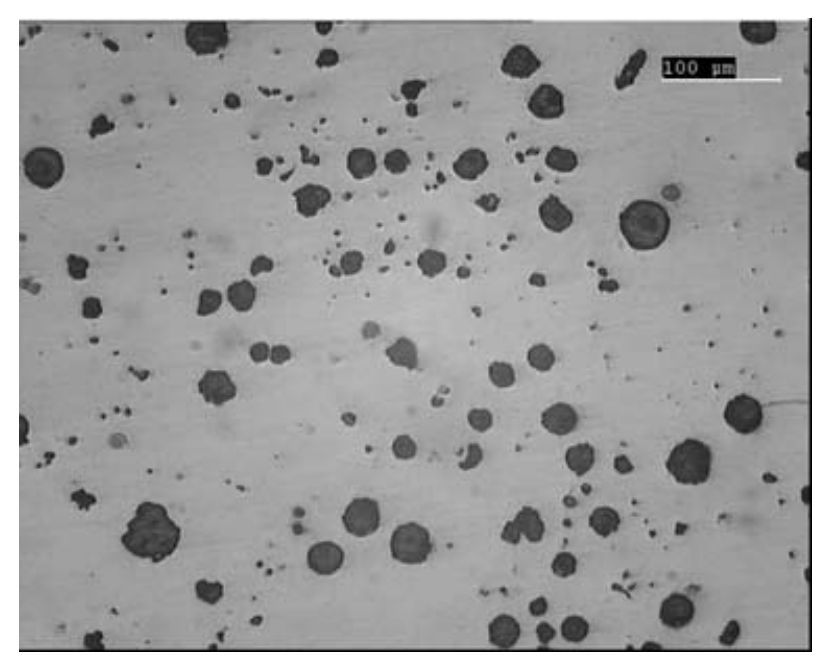

Fig. 2 Optical micrographs of cast iron GS51 with 5\% ferrite and $95 \%$ perlite.

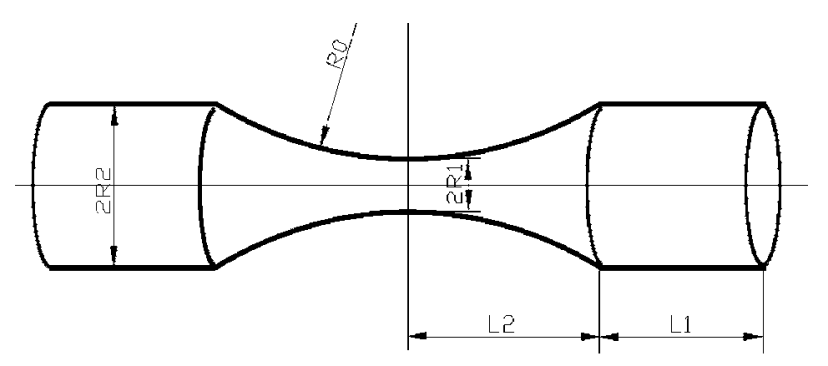

Fig. 3 Geometry of specimen.

(around 30 cycles). The refresh time of the camera varies between 0.83 and $100 \mathrm{~Hz}$. The pyrometer was calibrated on a blackbody reference. The sources of error associated with the pyrometer are often related to uncertainties on the emissitivy of the surface. To eliminate this problem, the specimen surface was covered with a strongly emissive black painting. The various fatigue tests, which were performed, and mechanical properties are summarised in Table 2.

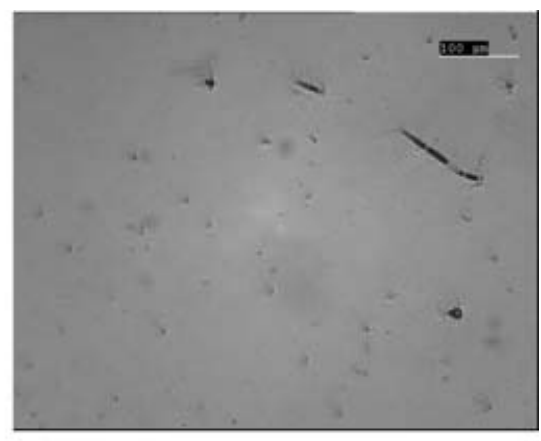

(b)

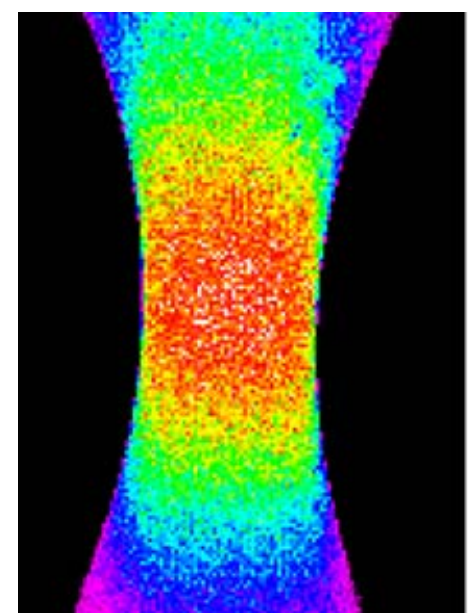

Temperature in $\mathrm{C}$

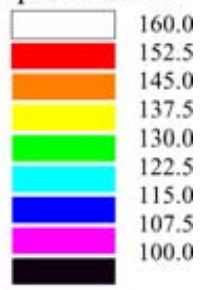

Fig. 4 Temperature field at the specimen surface; cast iron GS51 after $10^{7}$ cycles and with stress amplitude of $120 \mathrm{MPa}$.

\section{RESULTS AND DISCUSSION}

\section{Heat dissipation phenomenon without failure during the fatigue test}

Figure 4 illustrates the type of temperature distributions observed on the cast iron specimen surface after $10^{7}$ cycles (test number 3). Note that the temperature is heterogeneous along the axis of the specimen and is maximal at the centre of the useful part of the specimen. This temperature field can be explained by the heterogeneity of the strain and stress and by the thermal losses related to conduction along the axis of the specimen.

Figure 5 shows the temperature variation at the centre of the specimen as a function of cycle number for two different stress levels (tests 3 and 4). It should be noted that a fast increase in temperature at the beginning of the test is followed by a stabilization corresponding to a balance between the mechanical energy dissipated into heat and the energy lost by convection and radiation at the specimen surface and by conduction inside the 


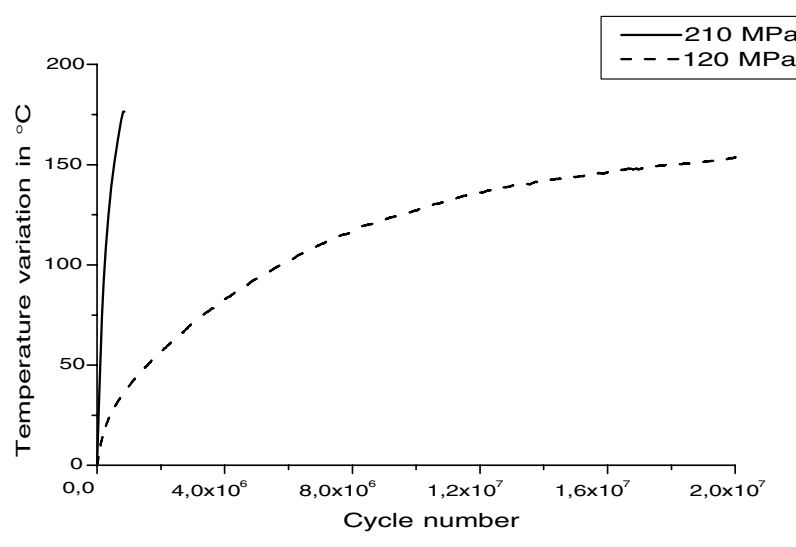

Fig. 5 Temperature variation at the centre of the specimen; cast iron GS51; tests 3 and 4.

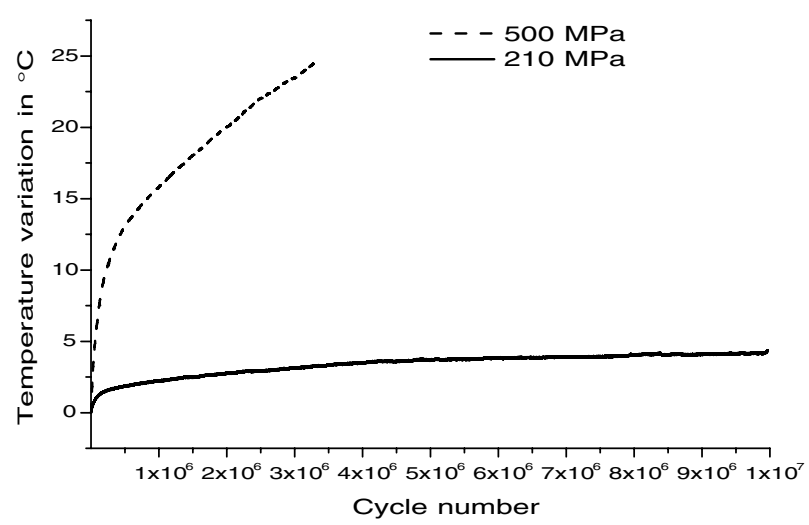

Fig. 6 Temperature variation at the centre of the specimen; AISI 52100 steel; tests 1 and 2 .

specimen. Thus, this increase in temperature is directly related to the mechanical energy dissipated into heat. Although the stress in the specimen is lower than the elastic limit, the dissipated energy comes from internal material damping and local plastic deformation at the microscopic scale.

Figure 5 also shows the influence of stress on the temperature evolution. Higher stress, the increase in temperature is larger and the energy dissipated is more significant. This observation can also be checked in Fig. 6 in the case of the AISI 52100 steel. We can also notice that the same stress amplitude of $210 \mathrm{MPa}$ for the cast iron GS51 and for the AISI 52100 steel generates a more significant increase in the temperature in the case of the cast iron. Indeed, the stress amplitude of $210 \mathrm{MPa}$ corresponds to $45 \%$ of the cast iron GS51 yield strength and $18 \%$ of the AISI 52100 steel elastic limit. Rather it is seen that the increase in the temperature is related to the amplitude ratio of the constraint by the elastic limit.

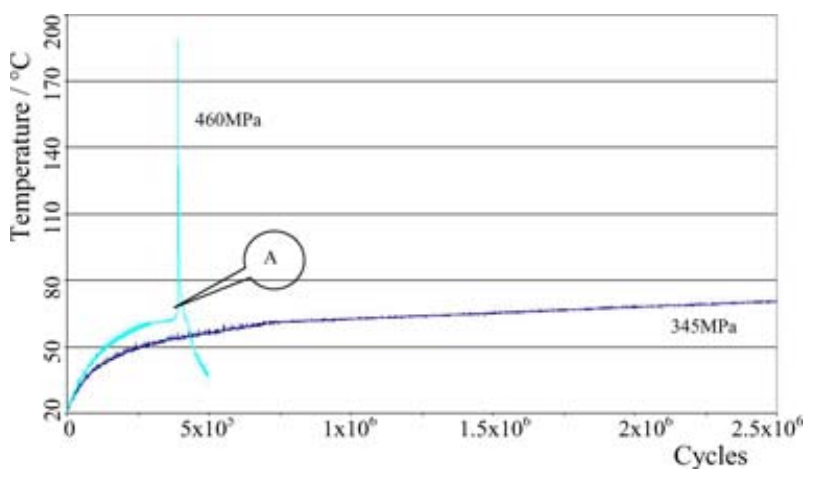

Fig. 7 Temperature profiles of $42 \mathrm{CD} 4$ tested at different stress level $(f=20 \mathrm{kHz})$; tests 5 and 6 .

\section{Heat dissipation in fatigue with fracture}

It can be observed that the temperature field in the centre of the specimen becomes strongly heterogeneous just before the rupture. Figure 7 illustrates the evolution of the variation in temperature at the point where the temperature is a maximum during the fatigue rupture of the $42 \mathrm{CD} 4$ steel. It is seen that the temperature increases quickly just before the rupture. At a stress amplitude of $345 \mathrm{MPa}$ the specimen did not fail and at an amplitude of $460 \mathrm{MPa}$ failure occurred at $3.092 \times 10^{5}$ cycles. In the test, an advanced, high-speed, and high-sensitivity infrared imaging system was used to record the temperature changes during ultrasonic fatigue test. The experimental results from thermal data acquisition for the $42 \mathrm{CD} 4$ specimen are shown in Fig. 8. All temperature measurements were made at a rate of $25 \mathrm{~Hz}$, i.e. 25 thermal images per second. For each thermal measurement, the temperature distribution over the specimen gage section was extracted from the acquired data.

Figure 8a shows an enlargement of the evolution of the temperature variation just before the failure in the case of the 42CD4 steel for a stress amplitude of $460 \mathrm{MPa}$ (test 6). The corresponding data in Fig. $8 \mathrm{~b}$ shows various temperature fields on the specimen surface (test 6). Figure 9 shows various temperatures fields for another fatigue specimen with a longer fatigue life; we can see that the local temperature increases sharply just before the fatigue failure. Thus, the failure is preceded by a damage phase where the temperature increases locally.

From Fig. $8 \mathrm{a}$ and b, the number of cycles corresponding to the earliest thermal detection of the start of this damage phase can be determined. From the thermal image, we can see, in the early cycles, the temperature is heterogeneous in the gage section; there is no local temperature evolution. At approximately $4.05 \times 10^{5}$ cycles for the test 6 and $1.7615 \times 10^{7}$ cycles for the test 5 ; local temperature evolution occurred, implying that the microcrack was initiated. So, after recording a number of fatigue failures 


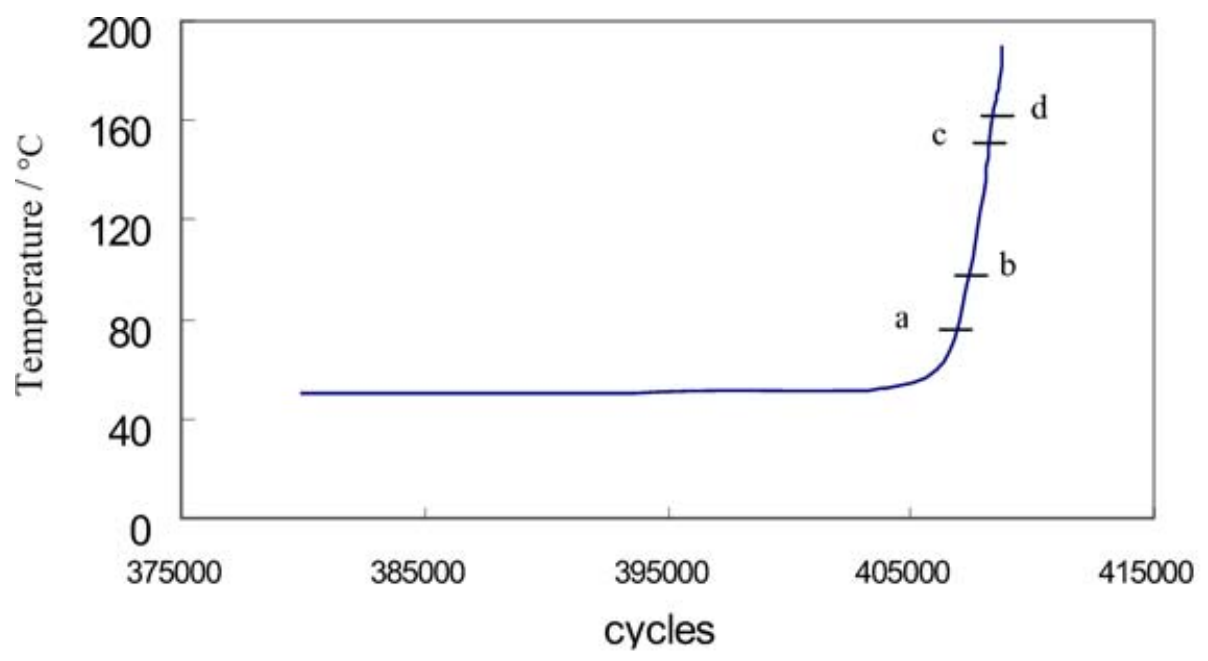

(a)

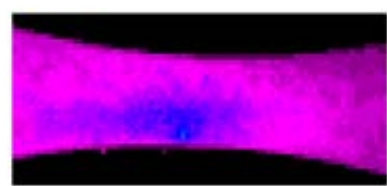

(1) $4.074 \times 10^{5}$ cycles

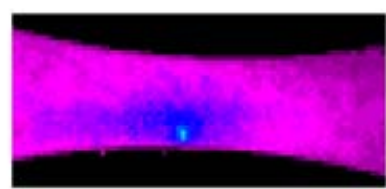

(2) $4.082 \times 10^{5}$ cycles

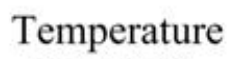

field in $\mathrm{C}$

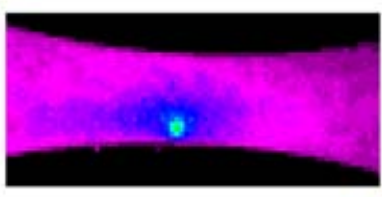

(3) $4.090 \times 10^{5}$ cycles

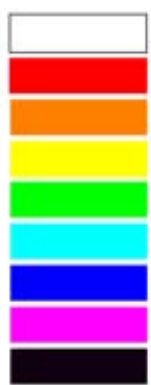

196.0

174.8

153.5

132.3

111.0

89.8

68.5

47.3

26.0

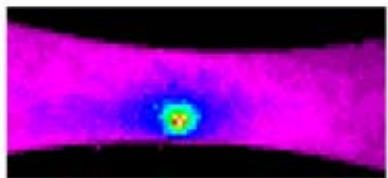

(4) $4.098 \times 10^{5}$ cycles

(b)

Fig. 8 Temperature field just before rupture; 42CD4 steel with stress amplitude of $460 \mathrm{MPa}$; test 6 .

in specimens, the durations of the damage phase can be determined as being about 5000 cycles.

Fatigue test results for 42CD4 are given in Fig. 10. The fatigue limit decreases considerably from the mega to the gigacycle range and the scatter of the results is very high. A step is observed in the $\mathrm{S}-\mathrm{N}$ curve when the load is in tension-compression. The results illustrate that fatigue rupture can occur beyond $10^{9}$ cycles 


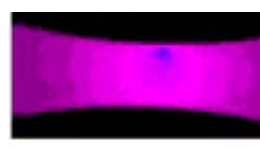

(1) $1.76188 \times 10^{7}$ cycles

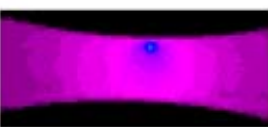

(2) $1.7619 \times 10^{7}$ cycles

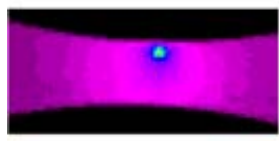

(3) $1.76192 \times 10^{7}$ cycles

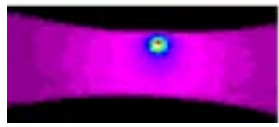

(4) $1.76194 \times 10^{7}$ cycles

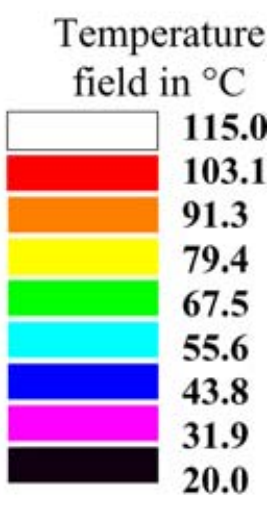

Fig. 9 Temperature field just before rupture; 42CD4 steel with stress amplitude of $425 \mathrm{MPa}$; test 5 .

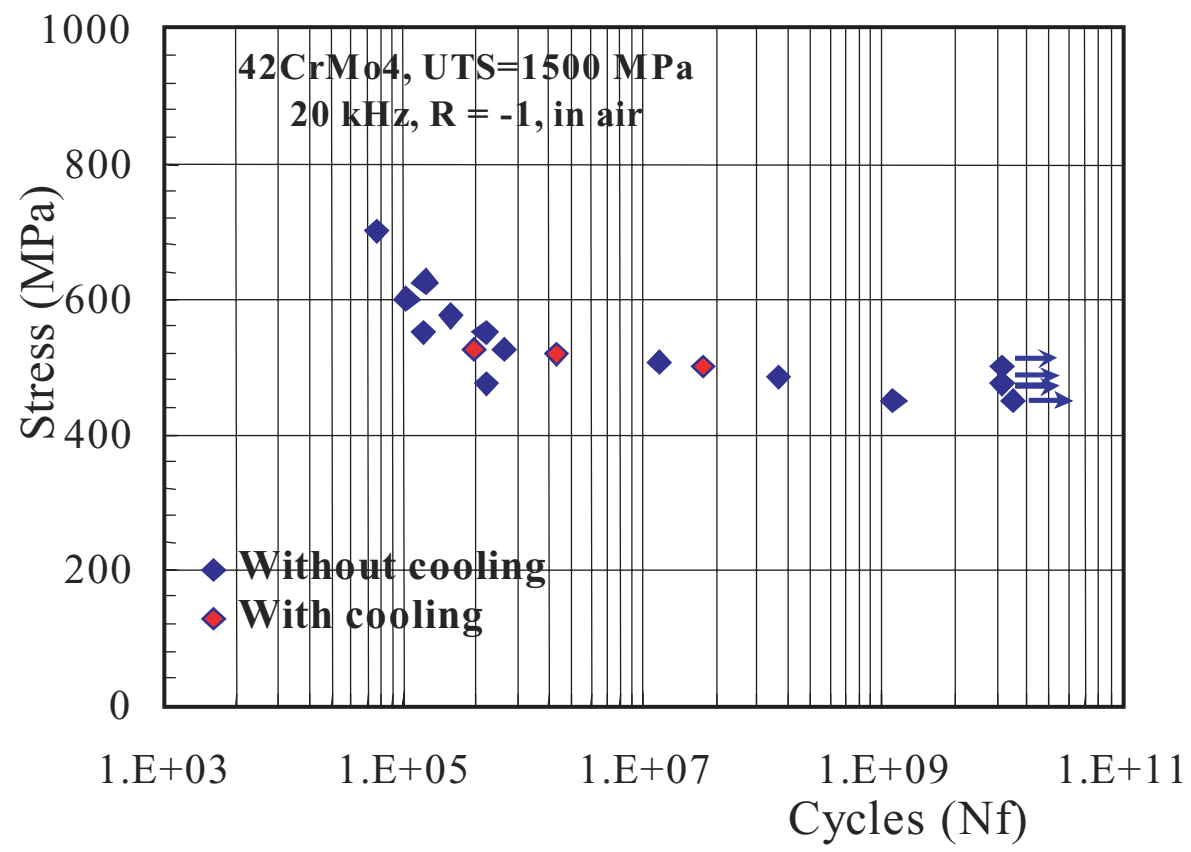

Fig. 10 Fatigue test results of $42 \mathrm{CD} 4(20 \mathrm{kHz}, R=-1$ in air).

and the difference in fatigue resistance decreases by 150 $\mathrm{MPa}$ between $10^{6}$ and $10^{10}$ cycles under these conditions. In fact, different initiation mechanisms exist to explain why always failure occurs at $10^{9}$ cycles. ${ }^{10}$ These mechanisms depend strongly on the microstructure of materials.

Besides, in the high cycle regime, there is no evident difference in the fatigue strength of 42CD4 between specimens tested with cooling and without cooling air (shown in Fig. 10) In fact, the difference in surface temperature between the cooled and uncooled specimens at $400 \mathrm{MPa}$ is approximately $40{ }^{\circ} \mathrm{C}$, such a small increase in temperature would not be expected to change the fatigue strength in the high cycle regime. In addition, as all specimens failed from subsurface flaws, any differences in internal temperatures would not be expected to influence the results. However, for the cast iron GS51, the difference in surface temperature between the cooled and uncooled specimens at $210 \mathrm{MPa}$ is more than $100{ }^{\circ} \mathrm{C}$, so the influence of temperature should be considered, besides, fatigue crack initiation of AISI 52100 specimens always begins from an internal defect, so, the difference in internal temperature would affect the fatigue strength. This point will be explored further in another paper. 


\section{Fractography of the fatigue specimens}

Figure 8 illustrates the temperature evolution at the point where the temperature is a maximum during the fatigue rupture of the $42 \mathrm{CD} 4$ sample subjected to $20 \mathrm{kHz}$ frequency cyclic loading. Figure $8 \mathrm{~b}$ shows the temperature obtained at approximately $4 \times 10^{5}$ cycles just before the specimen ruptured. The images show the heating progression and its diffusion away from the damage zones. It can be seen in the figures that damage was present after the samples were subjected to fatigue loading. Since plastic deformations always dissipate heat, the temperature will increase in the regions undergoing plastic strain. Thus the local plastic deformation region becomes visible on the thermograph, with the accumulation of local plastic deformation, the local high-temperature region becomes larger. The damage mechanisms of the steel are predominantly local microstructure plastic deformation. When the accumulation of local plastic deformation reached a crack threshold value, which is very small, small crack propagation occurred. The fractographic analysis shows that fatigue crack initiation is from an inclusion (shown in Fig. 11). So, the local plastic deformation around the subsurface inclusion in the steel is the reason for fatigue damage, and is the cause for increase in the temperature.

From Fig. 8, it can be seen that the temperature rises sharply when the small crack around the interior inclusion begins to propagate, and the maximum temperature of the specimen rises more than $100{ }^{\circ} \mathrm{C}$ in 4000 cycles.

Figure 12 shows the fracture surface obtained from the specimen (the temperature field just before rupture is shown in Fig. 9), which occurred beyond $10^{7}$ cycles. The observations of the failure surfaces for $42 \mathrm{CD} 4$ showed that cracks initiated from under or near the surface gave mainly flat and smooth facets for the given test conditions. The location of crack initiation or fatigue strength/life depends on the position, form, type, size and number of inclusions as a function of the number of cycles, $N_{\mathrm{f}}$. This aspect must be also related to the stress gradient around the inclusion. For specimen with a longer fatigue life, fatigue initiation is from a small inclusion, it corresponding to the temperature field, in the site of inclusion, it has lower temperature and small high temperature zone. However, for the $42 \mathrm{CD} 4$ steel, there is no fatigue crack did not initiate from the internal inclusion due to its location and shape of the inclusion.

The local temperature evolution in the fatigue specimen just before fracture highlighted the process of small crack growth, so the small crack growth life can be obtained by measuring the temperature field just before rupture. Recently, Paris has estimated crack growth life from the $\mathrm{d} a / \mathrm{d} N$ curve in the gigacycle range with a mathematical model. ${ }^{1}$ Based on the model, the small crack growth life, it was found to be only a small part of total fatigue
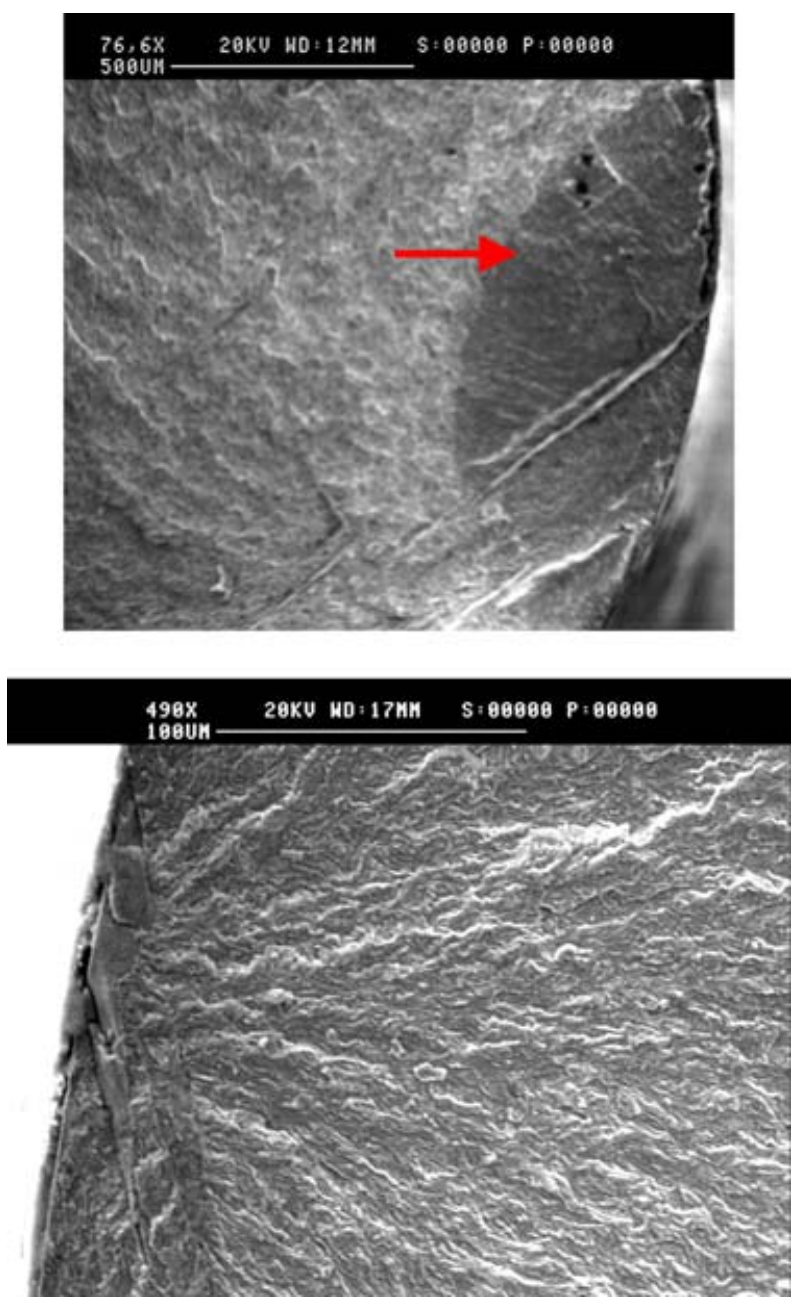

Fig. 11 Fracture surfaces due to non-metallic inclusions (at the surface $)$ in microstructure of $42 \mathrm{CD} 4 \mathrm{~T}\left(R=-1,20 \mathrm{kHz}, N_{\mathrm{f}}=1 \times\right.$ $10^{6}$ cycles).

life, which agrees fairly well with the results obtained from non-destructive evaluations. Non-destructive evaluation approach can describe effectively the process of small crack growth. The distribution in the ultrasonic fatigue specimen can describe effectively the process of small crack growth.

\section{CONCLUSION}

The temperature field in ultrasonic fatigue specimens has been measured to characterize the accumulated fatigue damage; an infrared camera was used to furnish fast non-contact temperature measurements at high local resolution for damage assessment. On the basis of analysing the temperature evolution in specimen, the relationship between temperature evolution and the fatigue damage mechanism and the effect of the temperature 

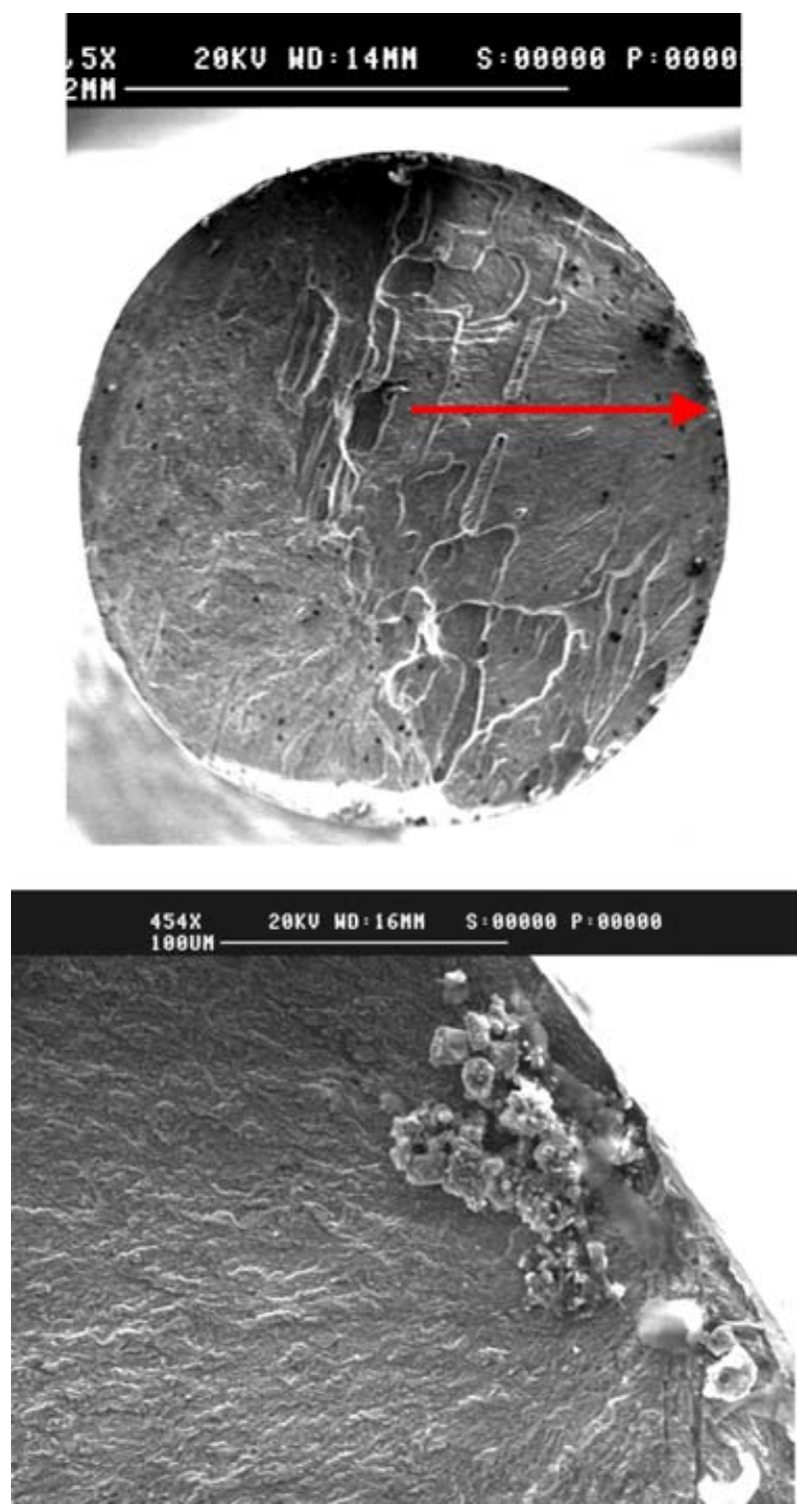

Fig. 12 Fracture surface due to non-metallic inclusions (under jacket) in microstructure of $42 \mathrm{CD} 4 \mathrm{~T}\left(R=-1,20 \mathrm{kHz}, N_{\mathrm{f}}=7.1 \times\right.$ $10^{7}$ cycles).

of the fatigue specimen on the fatigue life have been discussed. The key observations and analysis of energy dissipation in the ultrasonic fatigue testing can be summarized:

1 The mean temperature rise during an ultrasonic fatigue test is generally related to the internal damping of material, the temperature evolution in the fatigue specimen is dependent on not only the amplitude of cyclic loading but also the rate of loading.

2 Fatigue damage process can be detected by infrared images; and the temperature evolution is related to the local plas- tic deformation of the alloy or the microstructural damage process. The temperature of the specimen increases sharply when the microcrack begins to propagate. The temperature evolution reflects the fatigue damage process and this is consistent with results calculated by the Paris fatigue life model, that is, small crack growth is a very small part of the life of a fatigue specimen with a long fatigue life.

3 Under fully reversed, constant amplitude loading conditions at $20 \mathrm{kHz}, 42 \mathrm{CD} 4$ steel exhibits a continual gentle downward slope in the high cycle regime, the effects of temperature increase does not appear. However, for the cast iron GS51, the difference in surface temperature between the cooled and uncooled specimens at $210 \mathrm{MPa}$ is more than $100{ }^{\circ} \mathrm{C}$, and the influence of temperature should be considered. Besides, fatigue crack initiation in AISI 52100 specimens is always from an internal defect, and so, the difference in internal temperature would characterise the fatigue strength.

\section{Acknowledgements}

This project was carried out at ITMA-CNAM in Paris, which is Professor C. Bathias' research laboratory.

The authors are indebted to Professor C. Bathias, director of ITMA, for scientific and financial support of this research.

\section{REFERENCES}

1 Bathias, C. and Paris, P. C. (2004) In: Gigacycle Fatigue in Mechanical Practice. Marcel Dekker. Section 7, and ISBN 0-8247-2313-9.

2 Esin, A. and Jones, W. J. D. (1966). A theory of fatigue based on the microstructural accumulation of strain energy. Nucl. Eng. Des. 6, 292-297.

3 Jiang, L., Wang, H. and Liaw, P. K. (2001). Characterization of the temperature evolution during high-cycle fatigue of the ULTIMET super alloy, experiment and theoretical modelling. Metal. Mater. Trans. 32A, 2279-2296.

4 Lazan, B. J. (1964) Internal friction, damping, and cyclic plasticity. ASTM STP 378, ASTM, 47-87.

5 Puskar, A. (1977) The thermal activation of cumulative fatigue damage at ultrasonic frequencies. Ultrasonics 5, 124-128.

6 Luong, M. P. (1995) Infrared thermographic scanning of fatigue in metals. Nucl. Eng. Des. 158, 363-376.

7 Luong, M. P. (1998) Fatigue limit evaluation of metals using an infrared thermographic technique. Mech. Mater. 28, 155-163.

8 Maquin, F. and Pierron, F. (2005) Refined Experimental Assessment of Heat Dissipation in Cyclic Loading of Metals. Proceeding on the SEM International Conference. Portland, Oregon, Vol. 249, session no. 063.

9 Xue, H. Q., and Bathais, C. (2004) The analysis of the fatigue specimens at the high frequency, Proceeding on the VHCF-3, Kyoto, Japan, pp. 456-463.

10 Bayraktar, E., Marines, Garcia I. and Bathias, C. (2004) Failure mechanisms of automotive metallic alloys in very high cycle fatigue range, Proceedings on the VHCF-3, Kyoto, Japan, pp. $124-131$. 